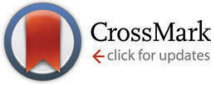

Cite this: Chem. Commun., 2016, 52,4235

Received 15th January 2016, Accepted 19th February 2016

DOI: $10.1039 / \mathrm{c} 6 \mathrm{cc00405a}$

www.rsc.org/chemcomm

\section{Selective, non-covalent conjugation of synthetic peptides with recombinant proteins mediated by host-guest chemistry $\dagger$}

\author{
R. J. Gubeli, ${ }^{a}$ S. Sonzini, ${ }^{b}$ A. Podmore, ${ }^{a}$ P. Ravn, ${ }^{c}$ O. A. Scherman ${ }^{{ }^{b}}$ and \\ C. F. van der Walle*a
}

More recently, cucurbit $[n]$ urils have emerged as a family of hosts able to bind to guest molecules with unprecedented (up to femtomolar) affinity. ${ }^{8,9}$ Cucurbit[8]uril (CB[8]) has a large cavity size and so possesses the unusual ability to accommodate two guests simultaneously, commonly forming a charge-transfer complex between an electron-poor 1st guest and an electronrich 2nd guest (Fig. 1A). ${ }^{10-12} \mathrm{CB}[8]$ has been applied to the assembly of polymer-protein ${ }^{13}$ and protein-protein ${ }^{14}$ conjugates, but in these studies derivatisation of the protein with guest moieties was necessary prior to the host-guest assembly. A strategy avoiding protein derivatisation while still facilitating host-guest assembly would be much more straightforward and advantageous for biological applications.

Inspired by studies showing that $\mathrm{CB}[8]$-mediated heterodimeric complexes can be formed with tryptophan (Trp) residues in short peptides ${ }^{15,16}$ we reasoned that $\mathrm{CB}[8]$ could be capable of

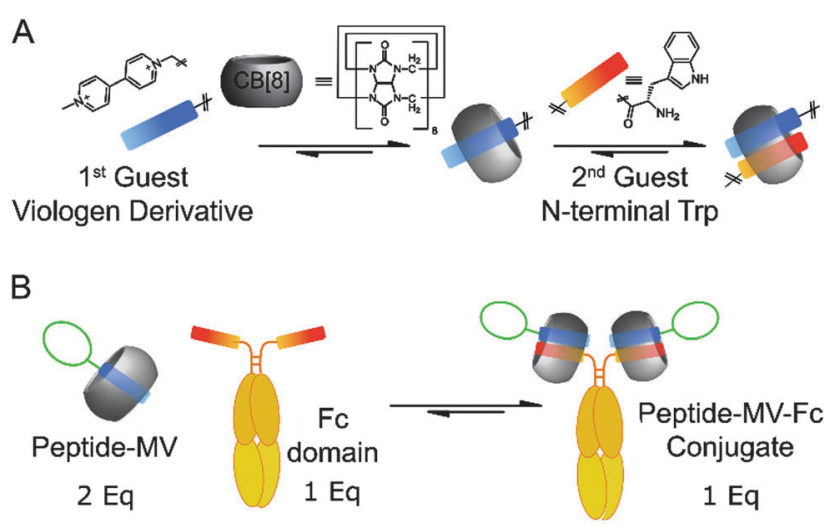

Fig. 1 Non-covalent conjugation of synthetic peptides with recombinant protein domains mediated by $\mathrm{CB}[8]$. (A) Molecules harbouring a 1st guest moiety such as a methyl viologen derivative (MV) are specifically linked to $\mathrm{N}$-terminal tryptophan (Trp; 2 nd guest) residues on recombinant proteins by ternary complexation with the host CB[8]. (B) Peptide-Fc conjugations are generated by $\mathrm{CB}[8]$-mediated assembly of FC domains with synthetic peptides. The MV derivative was used as a trifluoroacetate salt (counterion not shown in the cartoon). 
conjugating derivatised peptide molecules to proteins appended with a Trp 'tag'. This selective heterodimerisation strategy is distinct from the $\mathrm{CB}[8]$ mediated polymerisation of Phe-Gly-Gly (FGG)-tagged glutathione-S-transferase ${ }^{17}$ and homodimerisation of FGG-tagged yellow fluorescent protein. ${ }^{18}$ Thus, we show that synthetic peptides derivatised with methyl viologen (MV) (the 1st guest) can be addressed to a specific Trp residue (the 2nd guest) at the protein surface via $\mathrm{CB}[8]$, forming a heteroternary complex (Fig. 1A). Using stopped-flow spectroscopy, we reveal the fast exchange kinetics that lead to the considerably high affinity of the ternary complex. Furthermore, we demonstrate that the protein-bound synthetic peptide maintains its functional activity towards its receptor target. By pioneering the $\mathrm{CB}[8]-$-mediated conjugation of synthetic molecules to recombinant proteins, this study paves the way to the design and development of next-generation therapeutics with enhanced properties provided by host-guest chemistry.

Trp is a hydrophobic amino acid, which generally favours internalisation in a folded protein; the establishment of a hydrophobic core is a key driver in the folding pathway of proteins. ${ }^{19}$ Therefore, in order to avoid protein conformational destabilisation, we genetically engineered a spacer consisting of four tetraglycineserine repeats between the protein body and the N-terminal 2nd guest Trp residue. Placing the Trp at the N-terminus of the protein also served to further stabilise the ternary host-guest assembly by facilitating interaction of the positively charged amino group with the carbonyl groups at the rim of $\mathrm{CB}[8] \cdot{ }^{15}$ In selecting a protein for conjugation, we chose the immunoglobulin Fc since it is therapeutically relevant, ${ }^{20}$ imparting desired biophysical stability and pharmacokinetic properties. ${ }^{21}$ The Fc domain naturally predominates as a covalently linked homodimer, thereby presenting two N-termini, which we genetically modified with Trp residues as 2nd guests for the host-guest assembly (Fig. 1B). For the synthetic molecule to be conjugated to the Fc domain, we selected linear and cyclic arginine-glycine-aspartic acid (RGD) peptides derivatised with MV (RGD-MV and cRGD-MV, respectively, Fig. S1A, ESI $\dagger$ ). RGD is the canonical ligand of the integrin $\alpha_{v} \beta_{3}$ receptor and its cyclic form led to the development of cilengitide, the first anti-angiogenic small molecule drug. ${ }^{22}$

Previous studies have shown that the association of RGD with nanoparticles and proteins can enhance their diagnostic and therapeutic benefits. ${ }^{23,24}$ It is noteworthy that the synthetic routes to peptidomimetics, which involve cyclisation and/or D-amino acids, preclude their genetic conjugation to proteins. The $\mathrm{CB}[8]-$ mediated host-guest assembly can achieve the conjugation of such peptidomimetics to proteins in an elegant manner, here resulting in a heteroternary supramolecular complex of 2 peptides bound via $\mathrm{CB}[8]$ to each N-terminal Trp of the Fc domain (Fig. 1B). We started analysing the sequential assembly of the ternary complex by isothermal titration calorimetry (ITC).

The precomplex of cRGD-MV with $\mathrm{CB}[8]$ was formed with a $1: 1$ stoichiometry and an equilibrium binding constant $\left(K_{\mathrm{a}}\right.$ : $6.3 \times 10^{5} \mathrm{M}^{-1}$, Fig. S2, ESI $\dagger$ ) which is in accordance to previous observations with MV-modified peptides. ${ }^{16}$ In a subsequent step, we tested the binding of the $\mathrm{cRGD} \mathrm{MV} \subset \mathrm{CB}[8]$ precomplex to the two N-terminal Trp guests of the recombinant Fc domain

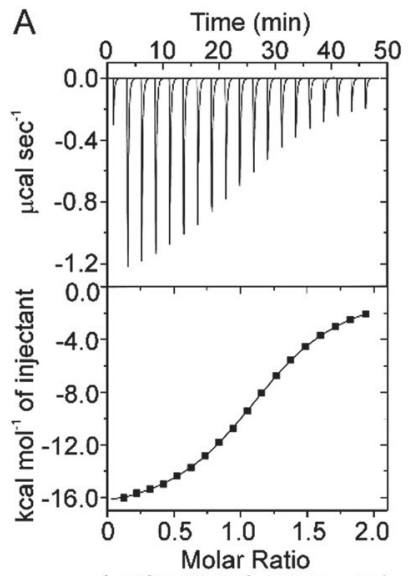

B
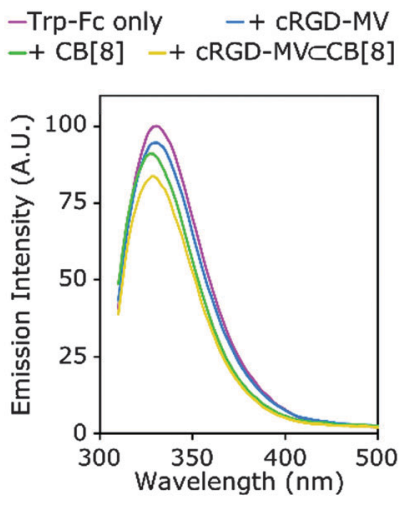

(cRGD-MVСCB[8]: Trp-Fc)

Fig. 2 Formation of $\mathrm{CB}[8]$-mediated peptide-Fc conjugations. (A) Binding of $C R G D-M V \subset C B$ [8] precomplex ( $500 \mu \mathrm{M}, 36.5 \mu \mathrm{L}$ in over 19 injections) to Fc domain harbouring $\mathrm{N}$-terminal tryptophans (Trp-Fc, $50 \mu \mathrm{M}$ ) characterised by ITC (FC-domain purity is shown in Fig. S3, ESI $\dagger$ ). (B) Changes in tryptophan fluorescence of Trp-Fc $(50 \mu \mathrm{M})$ were followed by the addition of equimolar amounts of CRGD-MV and $\mathrm{CB}[8]$ alone or in precomplex (cRGD-MV $\subset \mathrm{CB}[8]$ ).

Table 1 Kinetic and thermodynamic constants for ternary complex formation of $C R G D-M V \subset C B[8]$ with Trp-Fc

\begin{tabular}{lllll}
\hline $\begin{array}{l}\text { Temperature } \\
{\left[{ }^{\circ} \mathrm{C}\right]}\end{array}$ & $\begin{array}{l}K_{\mathrm{a}}(\mathrm{ITC})^{a} \\
{\left[10^{5} ; \mathrm{M}^{-1}\right]}\end{array}$ & $\begin{array}{l}k_{\mathrm{a}} \\
{\left[10^{6} ; \mathrm{M}^{-1} \mathrm{~s}^{-1}\right]}\end{array}$ & \multicolumn{1}{l}{$\begin{array}{l}k_{\mathrm{d}} \\
{\left[\mathrm{s}^{-1}\right]}\end{array}$} & $\begin{array}{l}K_{\mathrm{a}}^{b} \\
{\left[10^{5} ; \mathrm{M}^{-1}\right]}\end{array}$ \\
\hline 7.5 & $2.7 \pm 0.1$ & $29 \pm 1$ & $89 \pm 15$ & $3.3 \pm 0.7$ \\
10 & $2.6 \pm 0.2$ & $34 \pm 2$ & $105 \pm 23$ & $3.2 \pm 0.6$ \\
15 & $2.5 \pm 0.2$ & $41 \pm 2$ & $131 \pm 24$ & $3.1 \pm 0.6$ \\
37 & $2.3 \pm 0.3$ & $98 \pm 16^{c}$ & $364 \pm 42^{c}$ & $2.7 \pm 0.5$
\end{tabular}

${ }^{a}$ Equilibrium binding constants determined by ITC and separately. ${ }^{b}$ Equilibrium binding constants calculated from the ratio of $k_{\mathrm{a}}$ to $k_{\mathrm{d}}$. ${ }^{c}$ Kinetic constants extrapolated from measured values at lower temperature using the Arrhenius law.

(Fig. 2A, thermodynamic data in Table 1 and Table S1, ESI $\uparrow$ ). We were able to confirm a 1:1:1 stoichiometry of the host with the 1st and 2nd guest moieties, resulting in a molecular architecture wherein every $\mathrm{Fc}$ domain was conjugated with two cRGD-MV peptides $\left((\mathrm{cRGD} \mathrm{MV} \subset \mathrm{CB}[8])_{2} \subset \mathrm{Trp}-\mathrm{Fc}\right)$.

The precomplex cRGD-MV $\subset \mathrm{CB}[8]$ interacted with the 2nd guest Trp with a $K_{\mathrm{a}}$ of $2.3 \times 10^{5} \mathrm{M}^{-1}$ resulting from an enthalpically favourable contribution and an entropic penalty (Table S1, ESI $\dagger$ ), thereby confirming that we were able to transfer the binding characteristics observed with Trp in a short 3-amino acid oligopeptide ${ }^{15}$ to the 3-dimensionally folded Fc domain.

When we exchanged the N-terminal Trp residues of the $\mathrm{Fc}$ domain with tyrosine (Tyr-Fc, Fig. S4A, ESI $\dagger$ ), a 10-fold decrease in affinity was observed. Furthermore, an Fc domain with $\mathrm{N}$ terminal serines (Ser-Fc, Fig. S4B, ESI $\dagger$ ) did not show any interaction with the $\mathrm{CRGD}-\mathrm{MV} \subset \mathrm{CB}[8]$ precomplex.

This indicates that the host-guest assembly is directed with high specificity towards the exposed $\mathrm{N}$-terminal residues while excluding the other 8 Trp, 18 Tyr and 16 Phe residues, which are part of the hydrophobic core of the $\mathrm{Fc}$ domain (Fig. S5, ESI $\dagger$ ). 
To further demonstrate the selective $\mathrm{CB}[8]$ mediated assembly of the heteroternary complex, we followed the change in intrinsic Trp fluorescence of the Fc domain (Fig. 2B). Whereas the addition of cRGD-MV or $\mathrm{CB}[8]$ alone only led to a slight decrease in fluorescence, the quenching was much greater upon addition of the $\mathrm{cRGD}-\mathrm{MV} \subset \mathrm{CB}[8]$ precomplex. This, together with a less evident hypsochromic effect caused by the addition of the precomplex compared to $\mathrm{CB}[8]$ alone, indicates that the two guests indeed form a charge-transfer complex inside the $\mathrm{CB}[8]$ cavity. $^{25}$

In agreement with thermodynamic characterisation by ITC, no significant Trp fluorescence quenching effect of the cRGD-MV $\subset \mathrm{CB}[8]$ precomplex or its single components could be observed upon incubation with Ser-Fc (Fig. S6, ESI $\dagger$ ), again confirming that the host-guest assembly does not interfere with the folded structure of the Fc domain itself.

In an assay designed to be independent of the nature of the host and guest molecules, we monitored the change in molecular size of the synthetic peptide during the assembly of the ternary complex by fluorescence polarisation (Fig. S7, ESI $\dagger$ ). With this aim, we synthesised a linear RGD-MV peptide covalently modified with fluorescein at the N-terminus (FITC-RGD-MV, Fig. S1B, ESI $\dagger$ ). The addition of increasing concentrations of $\mathrm{CB}[8]$ to FITC-RGD-MV (300 $\mathrm{nM}$ ) resulted in an increase in polarisation of the FITC fluorophore at a $\mathrm{CB}[8]$ concentration around $1 \mu \mathrm{M}$, which agrees well with the dissociation constant $\left(K_{\mathrm{d}}=1 / K_{\mathrm{a}}=1.6 \mu \mathrm{M}\right)$ of the precomplex as measured by ITC. In a second step, we titrated Trp-Fc into a solution of assembled FITC-RGD-MV $\subset \mathrm{CB}[8]$ and again observed an increase in polarisation at a Trp-Fc concentration corresponding to the measured $K_{\mathrm{d}}$ of $5.2 \mu \mathrm{M}$ for the ternary complex (Fig. S7, ESI $\dagger$ ). Interestingly, at Trp-Fc concentrations higher than $15 \mu \mathrm{M}$, polarisation decreased again, which can be explained by the inclusion of two Trp moieties into the $\mathrm{CB}[8]$ host. $^{26}$ Although such a homodimeric $\operatorname{Trp}_{2} \subset \mathrm{CB}[8]$ complex is of lower affinity as compared to the heterodimeric assembly, its partial formation can be detected in this assay due to the high molar excess of Trp-Fc over the MV-modified peptide ( $>50$-fold).

Having defined the assembly mechanism of the heteroternary complex and associated affinity constants, we sought suitable analytical procedures for its characterization. A separation technique was considered most appropriate for the identification of potential side-products such as unconjugated protein species. We used asymmetric flow field flow fractionation (AF4) given its prior application for polymeric host-guest complexes. ${ }^{27}$ For the AF4 method, we changed the protein used in the host-guest assembly to the third fibronectin type III domain of human tenascin $\mathrm{C}$ $(\mathrm{Tn} 3) .^{28} \mathrm{Tn} 3$ is a small (13 kDa), monomeric protein and therefore shows a much higher proportional change in molecular size upon host-guest assembly with the peptide compared to the Fc domain (51 kDa), improving the separation of products by AF4. We expressed the Tn3 domain with a genetically introduced Trp guest at the $\mathrm{N}$-terminus followed by the tetraglycine-serine spacer and assembled it with the $\mathrm{CRGD}-\mathrm{MV} \subset \mathrm{CB}[8]$ precomplex, resulting in the cRGD-MV $\subset \mathrm{CB}[8] \subset \operatorname{Trp}-\mathrm{Tn} 3$ ternary complex. The free Trp-Tn3 domain was separated from its peptide-bound state at different molar ratios of cRGD-MV $\subset \mathrm{CB}[8]: \operatorname{Trp}-\mathrm{Tn} 3$ (Fig. S8, ESI $\dagger$ ).

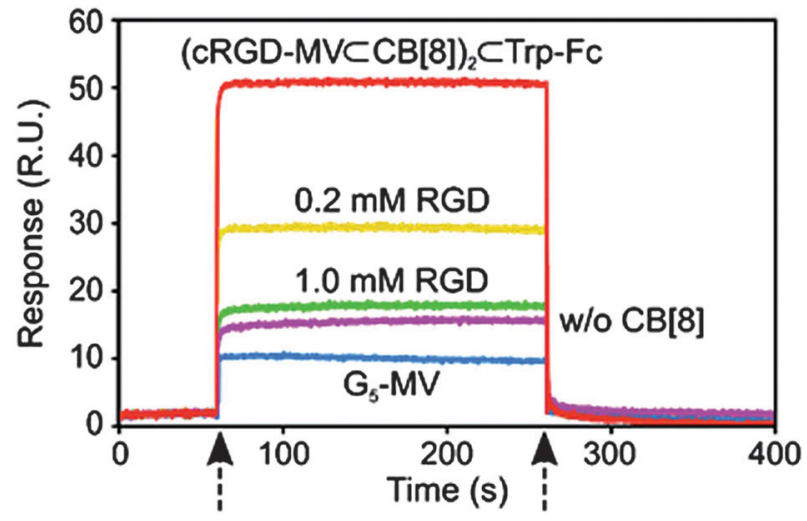

Fig. 3 Interaction of (CRGD-MV $\subset \mathrm{CB}[8])_{2} \subset \operatorname{Trp}-\mathrm{Fc}$ with its molecular target integrin $\alpha_{v} \beta_{3}$. Binding of $(C R G D-M V \subset C B[8])_{2} \subset \operatorname{Trp}-F c$ to immobilised integrins was followed by surface plasmon resonance (SPR). Competing RGD peptide was spiked into the assembled complex at 0.2 and $1 \mathrm{mM}$ leading to reduced binding levels similar to when $\mathrm{CB}[8]$ was omitted in the complex assembly (without $\mathrm{CB}[8]$, dark blue line). Background binding levels are represented by an assembled complex of Trp-Fc with $\mathrm{CB}[8]$ and G5-MV. Arrows indicate start and end of the sample injections.

For molar ratios of cRGD-MV $\subset \mathrm{CB}[8]: \operatorname{Trp}-\mathrm{Tn} 3>1$, representing saturation of the Trp-Tn3 domain, no further shift towards later elution times was observed, which demonstrates that the ternary complex did not significantly disassemble during separation. To corroborate the AF4 data, we applied a light scattering approach (Fig. S9, ESI $\dagger$ ) to independently confirm the change in molecular weight $\left(M_{\mathrm{w}}\right)$ from the free Trp-Tn3 domain $(14.5 \pm 0.2 \mathrm{kDa})$ towards the assembled cRGD-MV $\subset \mathrm{CB}[8] \subset$ Trp-Tn3 ternary complex $(16.4 \pm 0.3 \mathrm{kDa})$, which is in good agreement with the theoretically calculated values of 14.2 and $16.3 \mathrm{kDa}$, respectively.

Having confirmed that the heteroternary complex is forming and stable through purification, we further studied the on/off kinetics of the supramolecular assembly. Therefore, stoppedflow experiments were performed in which the decrease in intrinsic fluorescence of the 2nd guest Trp upon assembly of Trp-Fc with $\mathrm{cRGD}-\mathrm{MV} \subset \mathrm{CB}[8]$ was followed spectroscopically (Fig. S10, ESI $\dagger$ ). Pseudo-first order assembly conditions were established over three temperatures by altering the molar ratio of cRGD-MV $\subset \mathrm{CB}[8]: T r p-F c$, with at least a 5-fold excess of the 1st guest while keeping the concentration of Trp-Fc constant (Fig. S10C, ESI $\dagger$ ). We subsequently applied the method described by Appel et $a .^{29}$ to calculate the association and dissociation rate constants $\left(k_{\mathrm{a}}\right.$ and $\left.k_{\mathrm{d}}\right)$ at the respective temperatures (Table 1$)$.

Due to the fast kinetics of the ternary complex formation, we were only able to determine kinetic rate constants at temperatures below $15{ }^{\circ} \mathrm{C}$. However, the calculation of the Arrhenius activation energies of association $\left(\mathrm{Ea}_{\mathrm{a}} ; 29 \pm 4 \mathrm{~kJ} \mathrm{~mol}{ }^{-1}\right)$ and dissociation $\left(\mathrm{Ea}_{\mathrm{d}} ; 34 \pm 3 \mathrm{~kJ} \mathrm{~mol}^{-1}\right)^{29}$ allowed us to extrapolate the rate constants at higher temperatures, notably $37{ }^{\circ} \mathrm{C}$, both more relevant and predictive of behaviour in vivo.

Interestingly, both $k_{\mathrm{a}}$ and $k_{\mathrm{d}}$ become faster to almost the same degree with increasing temperature, thereby resulting in only a minimal temperature effect on the equilibrium binding constants. We were able to confirm the temperature stability of 
the complex independently by ITC (Table 1). Our obtained kinetics for ternary complex formation with Trp mainly differ in faster association rate constants ( $>10$-fold) as compared to previous studies using polymers with naphthalene as 2nd guests, ${ }^{29}$ which also translates into roughly 10 -fold higher equilibrium binding constants.

To demonstrate retained fully reversible RGD-mediated binding of the tertiary complex to integrin, the binding kinetics were characterised by surface plasmon resonance (SPR). We tested the binding of the $(\mathrm{cRGD}-\mathrm{MV} \subset \mathrm{CB}[8])_{2} \subset$ Trp-Fc complex to immobilised integrin $\alpha_{v} \beta_{3}$ (Fig. 3). As a negative control we conjugated Trp-Fc to a pentaglycine-MV peptide (G5-MV, Fig. S1A, ESI $\dagger$ ) resulting in $(\mathrm{G} 5-\mathrm{MV} \subset \mathrm{CB}[8])_{2} \subset$ Trp-Fc which lacks the integrin-binding motif. A strong response was observed upon incubating integrins with (cRGD-MV $\subset \mathrm{CB}[8])_{2} \subset$ Trp-Fc whereas an exchange of the peptide to G5-MV led to only a minor, unspecific response. Additionally, we were able to show that spiking of $(\mathrm{cRGD}-\mathrm{MV} \subset \mathrm{CB}[8])_{2} \subset \mathrm{Trp}-\mathrm{Fc}$ with increasing concentrations of integrin-competing linear RGD led to a decrease in response levels similar to when $\mathrm{CB}[8]$ was omitted in the complex thereby demonstrating the reversibility of integrinbinding by (cRGD-MV $\subset \mathrm{CB}[8])_{2} \subset$ Trp-Fc.

We successfully applied $\mathrm{CB}[8]$-mediated host-guest chemistry for the selective, heterodimeric conjugation of small synthetic molecules to recombinant proteins without the prior chemical modification of the protein. The detailed knowledge about the thermodynamics and kinetics presented here will enable the evolution of small moleculeprotein complexes, e.g. optimisation of protein- $\mathrm{CB}[8]$ interaction motifs, ${ }^{30}$ inclusion of repetitive, zipper-like host-guest complexes ${ }^{16}$ or applying strategies to decrease the entropic penalty of the assembly. ${ }^{8,9}$ We anticipate that this modular approach has transformative potential in drug design and development, offering increased freedom to select the protein and small molecule components of a drug conjugate to impart advantages regarding potency, stability and targeted delivery.

We thank Alexandra Rieck, Isabelle Sermadiras, Benjamin Kemp and Jennifer Spooner for help with the expression and purification of the Fc and Tn3 domains, Jefferson Revell and Jacky Metcalfe for help with the synthesis of modified peptides and Christel Veyssier for help with the light scattering experiments. RJG was supported by the MedImmune post-doctoral program. SS was supported by ERC Starting Investigator grant ASPiRe (No. 240629).

\section{Notes and references}

1 R. V. J. Chari, M. L. Miller and W. C. Widdison, Angew. Chem., Int. Ed., 2014, 53, 3796-3827.

2 G. Shimamoto, C. Gegg, T. Boone and C. Queva, mAbs, 2012, 4, 586-591.
3 P. Agarwal and C. R. Bertozzi, Bioconjugate Chem., 2015, 26, 176-192. 4 J. R. Junutula, H. Raab, S. Clark, S. Bhakta, D. D. Leipold, S. Weir, Y. Chen, M. Simpson, S. P. Tsai, M. S. Dennis, Y. Lu, Y. G. Meng, C. Ng, J. Yang, C. C. Lee, E. Duenas, J. Gorrell, V. Katta, A. Kim, K. McDorman, K. Flagella, R. Venook, S. Ross, S. D. Spencer, W. L. Wong, H. B. Lowman, R. Vandlen, M. X. Sliwkowski, R. H. Scheller, P. Polakis and W. Mallet, Nat. Biotechnol., 2008, 26, 925-932.

5 A. Dirksen, M. Madsen, G. Dello Iacono, M. J. Matin, M. Bacica, N. Stankovic, S. Callans and A. Bhat, Bioconjugate Chem., 2014, 25, 1052-1060.

6 R. E. McGovern, H. Fernandes, A. R. Khan, N. P. Power and P. B. Crowley, Nat. Chem., 2012, 4, 527-533.

7 L. Zhang, Y. Wu and L. Brunsveld, Angew. Chem., Int. Ed., 2007, 46, 1798-1802.

8 M. V. Rekharsky, T. Mori, C. Yang, Y. H. Ko, N. Selvapalam, H. Kim, D. Sobransingh, A. E. Kaifer, S. Liu, L. Isaacs, W. Chen, S. Moghaddam, M. K. Gilson, K. Kim and Y. Inoue, Proc. Natl. Acad. Sci. U. S. A., 2007, 104, 20737-20742.

9 S. Moghaddam, C. Yang, M. Rekharsky, Y. H. Ko, K. Kim, Y. Inoue and M. K. Gilson, J. Am. Chem. Soc., 2011, 133, 3570-3581.

10 Y. Ling, W. Wang and A. E. Kaifer, Chem. Commun., 2007, 610-612.

11 F. Biedermann, U. Rauwald, M. Cziferszky, K. A. Williams, L. D. Gann, B. Y. Guo, A. R. Urbach, C. W. Bielawski and O. A. Scherman, Chem. - Eur. J., 2010, 16, 13716-13722.

12 F. Biedermann and O. A. Scherman, J. Phys. Chem. B, 2012, 116, 2842-2849.

13 F. Biedermann, U. Rauwald, J. M. Zayed and O. A. Scherman, Chem. Sci., 2011, 2, 279-286.

14 D. A. Uhlenheuer, J. F. Young, H. D. Nguyen, M. Scheepstraa and L. Brunsveld, Chem. Commun., 2011, 47, 6798-6800.

15 M. E. Bush, N. D. Bouley and A. R. Urbach, J. Am. Chem. Soc., 2005, 127, 14511-14517.

16 J. J. Reczek, A. A. Kennedy, B. T. Halbert and A. R. Urbach, J. Am. Chem. Soc., 2009, 131, 2408-2415.

17 C. Hou, J. Li, L. Zhao, W. Zhang, Q. Luo, Z. Dong, J. Xu and J. Liu, Angew. Chem., Int. Ed., 2013, 52, 5590-5593.

18 H. D. Nguyen, D. T. Dang, J. L. J. van Dongen and L. Brunsveld, Angew. Chem., Int. Ed., 2010, 49, 895-898.

19 C. N. Pace, B. A. Shirley, M. McNutt and K. Gajiwala, FASEB J., 1996, 10, $75-83$.

20 P. M. Hogarth and G. A. Pietersz, Nat. Rev. Drug Discovery, 2012, 11, 311-U87.

21 B. Wu and Y. Sun, J. Pharm. Sci., 2014, 103, 53-64.

22 C. Mas-Moruno, F. Rechenmacher and H. Kessler, Anti-Cancer Agents Med. Chem., 2010, 10, 753-768.

23 X. Montet, M. Funovics, K. Montet-Abou, R. Weissleder and L. Josephson, J. Med. Chem., 2006, 49, 6087-6093.

24 S. J. Moore, M. G. H. Gephart, J. M. Bergen, Y. S. Su, H. Rayburn, M. P. Scott and J. R. Cochran, Proc. Natl. Acad. Sci. U. S. A., 2013, 110, 14598-14603.

25 H. J. Kim, J. Heo, W. S. Jeon, E. Lee, J. Kim, S. Sakamoto, K. Yamaguchi and K. Kim, Angew. Chem., Int. Ed., 2001, 40, 1526-1529.

26 L. M. Heitmann, A. B. Taylor, P. J. Hart and A. R. Urbach, J. Am. Chem. Soc., 2006, 128, 12574-12581.

27 Z. Huang, L. Yang, Y. Liu, Z. Wang, O. A. Scherman and X. Zhang, Angew. Chem., Int. Ed., 2014, 53, 5351-5355.

28 R. N. Gilbreth, B. M. Chacko, L. Grinberg, J. S. Swers and M. Baca, Protein Eng., Des. Sel., 2014, 27, 411-418.

29 E. A. Appel, R. A. Forster, A. Koutsioubas, C. Toprakcioglu and O. A. Scherman, Angew. Chem., Int. Ed., 2014, 53, 10038-10043.

30 L. C. Smith, D. G. Leach, B. E. Blaylock, O. A. Ali and A. R. Urbach, J. Am. Chem. Soc., 2015, 137, 3663-3669. 